\title{
ENDOSCOPIC FAT GRAFTING OF SMALL AND RESIDUAL TYMPANIC MEMBRANE PERFORATIONS- A CLINICAL STUDY
}

\author{
Shameem Ahamed Seere Veetil1, Githin Chempakathinal Rajendran², Aswin Mukundan ${ }^{3}$, Sandeep Kandoth ${ }^{4}$, Ambili Janardhanan 5 \\ ${ }^{1}$ Assistant Professor, Department of Otorhinolaryngology, Academy of Medical Sciences, Pariyaram, Kannur, Kerala. \\ ${ }^{2}$ Assistant Professor, Department of Otorhinolaryngology, Academy of Medical Sciences, Pariyaram, Kannur, Kerala. \\ ${ }^{3}$ Assistant Professor, Department of Otorhinolaryngology, Academy of Medical Sciences, Pariyaram, Kannur, Kerala. \\ ${ }^{4}$ Resident, Department of Otorhinolaryngology, Academy of Medical Sciences, Pariyaram, Kannur, Kerala. \\ ${ }^{5}$ Resident, Department of Otorhinolaryngology, Academy of Medical Sciences, Pariyaram, Kannur, Kerala.
}

\section{ABSTRACT}

\section{BACKGROUND}

Fat patch grafting is a simple effective alternative to conventional tympanoplasty in dealing with carefully selected small central tympanic membrane perforations. Despite its numerous advantages and relative ease of the procedure, many a times it has been underused.

\section{MATERIALS AND METHODS}

The study was conducted in the Department of Otolaryngology, Academy of Medical Sciences, Pariyaram, Kannur, Kerala over a period of 2 years on 44 ears. An endoscope-assisted fat patch grafting technique was used in our study.

\section{RESULTS}

The Male-to-Female ratio was 2.1: 1; 39 cases had complete closure of the perforation. So, the overall success rate of the study was around $89 \%$.

\section{CONCLUSION}

Fat graft myringoplasty is a simple, cost effective day care surgical procedure done under local anaesthesia. It is an under-utilised procedure by otologists for the treatment of tympanic membrane perforations. Through our study, we would like to emphasise the importance of this procedure done endoscopically for carefully selected cases, which has a very good success rate.

\section{KEYWORDS}

Fat graft; Myringoplasty; Tympanic Membrane Perforation; Chronic Suppurative Otitis Media.

HOW TO CITE THIS ARTICLE: Veetil SAS, Rajendran GC, Mukundan A, et al. Endoscopic fat grafting of small and residual tympanic membrane perforations- a clinical study. J. Evolution Med. Dent. Sci. 2017;6(50):3828-3831, D0I: $10.14260 /$ Jemds/2017/827

\begin{abstract}
BACKGROUND
Chronic Suppurative Otitis Media (CSOM) is one of the commonest pathologies an otolaryngologist comes across in the Outpatient Department. They present with ear discharge and hearing loss and with a perforation in the tympanic membrane. These range from small to a subtotal perforation. Tympanoplasty is the treatment of choice for CSOM and temporalis fascia is the commonest graft material used to close the perforation. The first attempt to close a perforation was done by Banzer in 1640, who inserted a small tube of Elkhorn covered with pig's bladder. ${ }^{1}$ Berthold, in 1878 used a full thickness free skin graft for tympanic membrane closure. ${ }^{2}$

Fat as a graft material for perforation can be seen across the literature.3,4,5,6,7 We have done this study to find out the efficacy of fat patch grafting in terms of closure of the perforation and prevention of ear discharge.
\end{abstract}

Financial or Other, Competing Interest: None.

Submission 03-04-2017, Peer Review 08-06-2017,

Acceptance 14-06-2017, Published 22-06-2017.

Corresponding Author:

Dr. Shameem Ahamed Seere Veetil,

Assistant Professor,

Department of ENT,

Academy of Medical Sciences,

Pariyaram, Kannur, Kerala.

E-mail: drshameemsv@gmail.com

DOI: $10.14260 /$ jemds $/ 2017 / 827$

\section{(c) $($ ) $९$}

\section{MATERIALS AND METHODS}

This is a prospective study conducted in the Department of Otolaryngology and Head and Neck Surgery, Academy of Medical Sciences, Pariyaram, Kannur, Kerala, India over a period of 2 years. The study was approved by the Institutional Ethical Committee. A total of 44 cases were selected for the study. These included primary and residual tympanic membrane perforations after tympanoplasty. Only patients above the age of 15 years were included in the study. All cases were done by the same author. The selection of patients for the procedure was done by the criteria laid down by Fiorio and Barbieri in their description of the surgical procedure (Table 1). The procedure was detailed to every patient including the technique, the site of harvesting the fat (ear lobule or abdominal fat), chances of failure and complications following which a full written informed consent was taken from the patient and their first degree relative. Among the 44 cases selected for the procedure, 3 cases were residual tympanic membrane perforations after tympanoplasty from elsewhere. Of all the cases, 3 cases had bilateral tympanic membrane perforations. A detailed history and clinical examination was done in all patients and hearing was assessed by tuning fork tests and pure tone audiogram. Only those cases with mild hearing loss were selected for the procedure. Appropriate laboratory investigations were also done before the surgical procedure. 


\section{Surgical Technique}

All the procedures were done under local anaesthesia after taking a full written informed consent from the patient. The patient was positioned in a supine position with a slight degree of head end elevation. Under strict sterile precautions, 3 quadrant local anaesthesia was given in the root of external auditory canal of the diseased ear using 2\% lignocaine with 1:200000 adrenaline. The ear canal was irrigated with normal saline and diluted povidone iodine solution after instilling a few drops of $4 \%$ lignocaine into the middle ear. With the assistance of a 0-degree otoendoscope, the margins of the tympanic membrane perforation were freshened with a micro pick. The medial surface of the tympanic membrane was gently scraped with a Rosen's round knife. Local infiltration was then given to the ear lobule or the periumbilical area depending on the harvesting site. A 5-mm incision was made. Fat was taken in a size approximately twice the size of perforation in a single piece. The incision was closed with simple sutures. The fat was then trimmed to the appropriate size for the closure of tympanic membrane perforation. Under endoscopic (0-degree otoendoscope) guidance, the fat was then taken with a straight pick and gently inserted into the tympanic membrane perforation in a dumbbell shaped fashion, so that half of the fat is bulging into the middle ear and half onto the external auditory canal. The outer part of the fat graft was then stabilised with steroidsoaked Gelfoam. The external auditory canal was packed with a large piece of antibiotic-soaked Gelfoam. The patient was then sent home after 2 hours of post-operative observation with oral antibiotics and analgesics and instructions for care of the operated ear. The patient was then assessed after 1 month and 3 months postoperatively. The outcome of the surgical procedure was assessed depending on the closure of the perforation and appearance of the tympanic membrane of the operated ear (Figures 1 and 2).

\section{RESULTS}

44 cases were selected for the study over a period of 2 years; 41 cases had unilateral tympanic membrane perforation and 3 cases had bilateral tympanic membrane perforations. In the 3 bilateral tympanic membrane perforations, the contralateral ear had medium or large central tympanic membrane perforations and were not included in the study. Out of the 44 ears selected, 3 cases were post tympanoplasty residual tympanic membrane perforations and the rest primary tympanic membrane perforations. The average operating time was 25 minutes and there were no complications in any of the cases in our study. All the cases were analysed at the end of first and third month with regard to the appearance of the tympanic membrane and closure of the tympanic membrane perforation.

The Male-to-Female ratio was 2.1:1 (30 males and 14 females). The age of the patients ranged from 16 to 40 years with mean age around 24 years; 39 cases had complete closure of the tympanic membrane perforation. In 5 cases, the operated ear had a residual perforation at the end of 3 months with no definite cause discernible; 4 failures occurred in primary tympanic membrane perforations and there was 1 failure in post tympanoplasty residual perforations. There was no significant difference in graft uptake rates in terms of the age and gender of the patients. So, the overall success rate of our study was around $89 \%$. The comparison with success rates of other similar studies are given in the table (Table 2).

Table 1. Criteria followed for admission to Fat Graft Myringoplasty ${ }^{8}$

1. Period of time elapsed from previous surgery equal to or longer than 6 months.

2. Perforation of the pars tensa, no larger than $5 \mathrm{~mm}$.

3. Non-marginal localisation, i.e. not involving the annulus or exposing the malleus handle.

4. Absence of calcific plaques or atrophic areas adjacent to the perforation.

5. Normal appearance of mucosa in the tympanic cavity.

6. Absence of any acute inflammation.

7. Absence of middle ear discharge in last 3 months.

8. No evidence of cholesteatoma.

9. No planned ossicular reconstruction.

10. Absence of major Eustachian tube dysfunction.

\begin{tabular}{|c|c|c|}
\hline Authors & $\begin{array}{c}\text { Operated } \\
\text { Ears }\end{array}$ & $\begin{array}{c}\text { Graft Uptake } \\
\text { Rate in \% }\end{array}$ \\
\hline Hegazy et al $^{9}$ & 68 & 88.2 \\
\hline Landsberg et al $^{10}$ & 38 & 81.6 \\
\hline Kim et al $^{11}$ & 46 & 87 \\
\hline Udaipurwala et al $^{12}$ & 22 & 95.2 \\
\hline Mitchell et al $^{13}$ & 56 & 91 \\
\hline Bertoli et al $^{14}$ & 73 & 80.8 \\
\hline Our Study & 44 & 88.6 \\
\hline
\end{tabular}

Table 2. Comparison between the Graft Uptake Rate of various Studies conducted on Fat Graft Myringoplasty

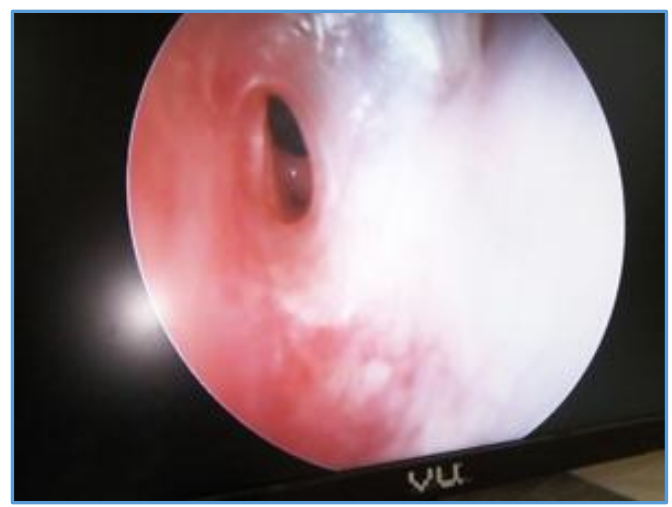

Figure 1. Small Anterior Residual Perforation Post Tympanoplasty

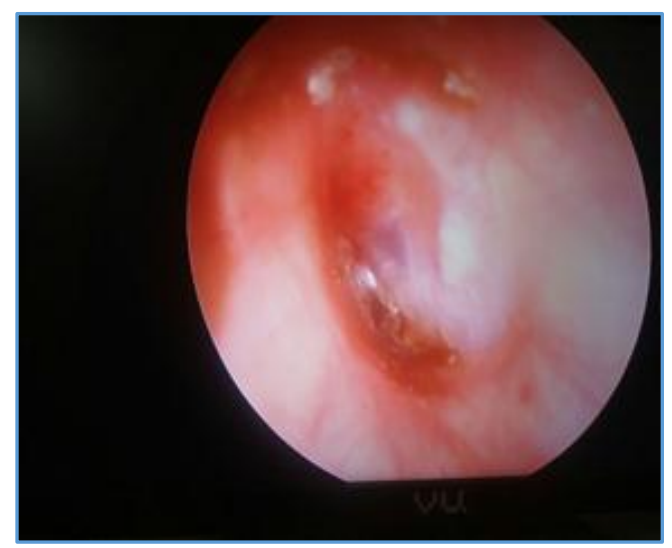

Figure 2. Fat Patch Grafting Postop. Appearance 


\section{DISCUSSION}

Wullstein and Zoellner popularised myringoplasty technique in 1951 for tympanic membrane perforations. Now with much improved optics and microsurgery techniques, it is still commonly practiced in modern days. Various graft materials have been used since then including skin, amniotic membrane, mucous membrane, dura mater, cornea, periosteum, perichondrium, vein, adipose tissue and temporalis fascia. Out of these, temporalis fascia has become the most popular grafting material worldwide for various reasons.

Fat patch grafting is a simple effective alternative to conventional tympanoplasty in dealing with carefully selected cases of small tympanic membrane perforations. Despite its numerous advantages and relative ease of the procedure, many a times it has been underused. ${ }^{7}$ The fat is readily available from ear lobe, abdomen and buttocks. Microscopic comparison of the fat from these three sources showed that the fat cells of the ear lobule were found to be more compact and contain more fibrous tissue. It provides scaffolding for the growth of tympanic membrane epithelium and mucous membrane by bridging the gap.

There are various advantages to fat graft myringoplasty. It does not need support from the middle ear side to prevent collapse like underlay grafts, especially at the area near the anterior annulus. The size of the graft in relation to the perforation, degree of lateral bulge of the fat plug and moistening of the lateral side of the graft are also considered to be important factors of success in the fat grafting procedure apart from careful selection of cases. Fat grafting is a very good option for small residual perforations after tympanoplasty with high success rates.

Fat is an active material, which contains angiogenic and survival factors like Monobutyrin, prostaglandins, interleukins 1 and 6, cytokines and tumour necrosis factor. These stimulate restoration and repair of the fibrous layer and promote revascularization, which are both essential for survival of the free flap. Fat graft eventually promotes various growth factors including Vascular Endothelial Growth Factor (VEGF), Transforming Growth Factor beta (TGF), Platelet Derived Growth Factor (PDGF) and Fibroblast Growth Factor (FGF). These promote the process of the tissue repair. Fat also contains a high population of multipotent cells, which is referred to as adipose-derived stem cells, which are similar in activity to those of the bone marrow-derived mesenchymal stem cells in the ability to differentiate into mesenchymal tissues, such as endothelial and fibrous types promoting the healing process of the tympanic membrane.

The principal aim of fat grafting is complete closure of small central tympanic membrane perforations with a relatively simple cost effective short procedure which require less skill, minimal tissue dissection and fewer potential complications. ${ }^{3,4}$ In our study, we have assessed the results of fat grafting of primary small central tympanic membrane perforations and post tympanoplasty residual tympanic membrane perforations using an endoscope-assisted technique.

Ringenburg was one of the first one to describe fat plug myringoplasty with a success rate of $87 \% .{ }^{15}$ Since then there have been many literatures on fat grafting with varying success rates. Although fat grafting is a simple procedure, it cannot be taken as an alternative to conventional tympanoplasty for tympanic membrane perforations in CSOM. The results are better if done on carefully selected cases. We had applied the selection criteria described by Fiorino and Barbieri (Table 1) for the procedure.

In our study, the mean age of the cases was 23.5 years. Shih et al described a success rate of $54 \%$ for children of 10 years and younger compared to $94 \%$ for children over 11 years of age.16 Chandrashekhar et al did not find any difference in success rates depending on age of the patient. ${ }^{17}$ We have selected only cases above 15 years in our study for ease of the procedure under local anaesthesia and less chances of upper respiratory infections, even though literature have shown that age may not be a factor in fat grafting. Ear lobule has been the harvesting site in most of our cases, except in some females who preferred abdomen fat due to fear of cosmetic problems in wearing earring. Fat from ear lobule is stiffer, lie in the same surgical field and easier to plug into the tympanic membrane perforation.

The size of the tympanic membrane perforation is another criterion pointed out by many studies. Fiorino and Barbieri have advised perforations of less than $5 \mathrm{~mm}$ size for Fat Myringoplasty. According to Kaddour et al, the size of the perforation should not exceed $30 \%$ of the size of the tympanic membrane. ${ }^{18}$ Terry et al did Fat Myringoplasty for perforations of varying sizes and found a success rate of $\mathbf{7 9 . 4 \%}$ for smaller perforations and $57.1 \%$ for perforations of larger sizes. ${ }^{19}$ We had chosen cases with tympanic membrane perforation of $5 \mathrm{~mm}$ or less than $25 \%$ of the tympanic membrane for the study in accordance with Fiorino and Barbieri et al. ${ }^{8}$

In our study, we had 5 failures in 44 cases with a success rate of $88.6 \%$. The failure cases we had were that of tympanic membrane perforations, which on followup after 1 month had a residual perforation. This was comparable to most of the studies done earlier (Table 2). Fiorino and Barbieri attributed the failure cases to immediate failure due to technical difficulties such as anterior perforation, inadequate graft support, poor vascular supply or infection and delayed failures due to tympanic membrane atrophy, infections or eustachian tube dysfunction with change of tympanic membrane structure. ${ }^{4}$ The size of the fat graft is also a cause for failure. The graft has to be double the size of the tympanic membrane perforation and should be laid as a dumbbell. Hegazy et al pointed out that graft size in relation to the perforation, degree of lateral bulge in the fat plug and moistening of the lateral side of the graft are important factors for the success of the procedure. ${ }^{9}$

Performing a Fat Myringoplasty is not without its own challenges. Finding an implant that is large enough to repair a large perforation in patients with a small lobule may be difficult. So the effectiveness is much more pronounced in case of small perforations. There is also the possibility of postsurgical lobule deformity, even though extremely rare. A sense of fullness in the ear and temporary tinnitus occur in some cases, probably caused by the long-term persistence of the graft block. Some patients may complain of wetness, which may be melting fat for a few weeks after surgery.

The advantage of fat grafting is that it is a simple costeffective procedure. We have done the procedure endoscopically, which gives good visualisation and magnified view. It is a relatively easy procedure with less technical skill and can be done as an office procedure. It can be done under 
local anaesthesia and post-operative complications are relatively nil. This can be used as a very good option for cases with small residual tympanic membrane perforation after tympanoplasty. The host cell replacement theory of Neuhof and the cell survival theory of Peter are the two histological theories put forward for fat grafting. ${ }^{20,21} \mathrm{~A}$ connective tissue capsule is formed outside the grafted fat, which ultimately forms a membrane.

\section{CONCLUSION}

An endoscope-assisted fat graft myringoplasty is a simple, cost-effective surgical procedure, often underutilised by otologists. It can be easily done under local anaesthesia and avoids extensive middle ear manipulation. We would like to emphasise the importance of this procedure for carefully selected cases yielding very good success rates in CSOM. It can be done for small tympanic membrane perforations due to trauma, infection, post tympanostomy tube extraction and post myringoplasty persistent residual perforations with good success rate without complication. Increasing the scale and the number of patients for this study would highlight more factors of success and failure for the procedure.

\section{ACKNOWLEDGEMENT}

This study was well supported by all staff of ENT Department, Academy of Medical Sciences, Pariyaram, Kannur, Kerala. We would also like to thank the staff of Department of Anaesthesia, Academy of Medical Sciences, Pariyaram, Kannur, Kerala and all Staff of Operation Theatre Complex, Academy of Medical Sciences, Pariyaram, Kannur, Kerala for the successful conductance of our study.

\section{REFERENCES}

[1] Benzer M. Disputatio de auditionelaesa. Trans Am acad Ophthal molotolaryngol 1963;67:233-59.

[2] Berthold E. Uber myringoplastic. Med-chircentralb 1879;14:195-207.

[3] Saliba I. Hyaluronic acid fat graft myringoplasty: how we do it. Clin Otolaryngol 2009;33(6):610-4.

[4] Imamoglu M, Isik AU, Acuner 0, et al. Fat-plug and paper-patch myringoplasty in rats. J Otolaryngol 1998;27(6):318-21.

[5] Hagemann M, Housler R. Tympanoplasty with adipose tissue. Laryngorhinootologie 2003;82(6):393-6.

[6] Liew L, Daudia A, Narula AA. Synchronous fat plug myringoplasty and tympanostomy tube removal in the management of refractory otorrhoea in younger patients. Int J Pediatr Otorhinolaryngol 2002; 66(3):291-6.
[7] Ozgursoy OB, Yorulmaz I. Fat graft myringoplasty: a cost-effective but underused procedure. J Laryngol Otol 2005;119(4):277-9.

[8] Fiorino F, Barbieri F. Fat graft myringoplasty after unsuccessful tympanic membrane repair. Eur Arch Otorhinolaryngol 2007;264(10):1125-8.

[9] Hegazy HM. Fat graft myringoplasty - a prospective clinical study. Egypt J Ear Nose Throat Allied Sci 2013;14(2):91-5.

[10] Landsberg R, Fishman G, DeRowe A, et al. Fat graft myringoplasty: results of a long-term follow-up. J Otolaryngol 2006;35(1):44-7.

[11] Kim DK, Park SN, Yeo SW, et al. Clinical efficacy of fat-graft myringoplasty for perforations of different sizes and locations. Acta Otolaryngol 2011;131(1):22-6.

[12] Udaipurwala IH, Farrukh MS, Shaikh SM, et al. Efficacy of fat plug myringoplasty in small and dry perforations of pars tensa. Med Channel J 2013;16:1-5.

[13] Mitchell RB, Pereira KD, Younis RT, et al. Bilateral fat graft myringoplasty in children. Ear Nose Throat J 1996;75(10):652, 655-6.

[14] Bertoli GA, Barbaro M, Giangande V, et al. Fat graft myringoplasty: An office procedure for the repair of small perfoations of the tympanic membrane. Mediterr J Otol.

[15] Ringenberg JC. Fat graft tympanoplasty. Laryngoscope 1962;72(2):188-92.

[16] Shih L, de Tar T, Crabtree JA. Myringoplasty in children. Otolaryngol Head Neck Surg 1991;105(1):74-7.

[17] Chandrasekhar SS, House JW, Devgan U. Pediatric tympanoplasty. A 10-year experience. Arch Otolaryngol Head Neck Surg 1995;121(8):873-8.

[18] Kaddour HS. Myringoplasty under local anaesthesia: day case surgery. Clin Otolaryngol Allied Sci 1992;17(6):567-8.

[19] Terry RM, Bellini MJ, Clayton MI, et al. Fat graft myringoplasty-a prospective trial. Clin Otolaryngol Allied Sci 1988;13(3):227-9.

[20] Neuhof H. The transplantation of tissues. New York: D Appleton and Co 1923.

[21] Peer LA. Transplantation of tissues. Vol: 2, Transplantation of fat. Baltimore: Williams and Wilkins 1959. 